Friends and Intelligence

\title{
Could Peers Influence Intelligence during Adolescence? An Exploratory Study
}

\author{
Ryan Charles Meldrum, $\mathrm{PhD}$ (corresponding author) \\ Department of Criminal Justice \\ Steven J. Green School of International and Public Affairs \\ Florida International University \\ 11200 SW $8^{\text {th }}$ St., PCA-364B \\ Miami, FL 33199 \\ United States of America \\ 305-348-5849 \\ rmeldrum@fiu.edu \\ Jacob T.N. Young, PhD \\ School of Criminology and Criminal Justice \\ Arizona State University \\ 411 N. Central Ave., Suite 639 \\ Phoenix, AZ 85004 \\ United States of America \\ 602-496-1343 \\ Jacob.Young.1@asu.edu \\ Nicholas Kavish, BA \\ Department of Psychology \& Philosophy \\ Sam Houston State University \\ Campus Box 2447 \\ Huntsville, Texas 77341-2447 \\ United States of America \\ nak012@shsu.edu \\ Brian B. Boutwell, PhD \\ Criminology \& Criminal Justice \\ School of Social Work \\ Department of Epidemiology (Secondary Appointment) \\ College for Public Health \& Social Justice \\ Department of Family and Community Medicine, School of Medicine (Secondary Appointment) \\ Saint Louis University \\ 3550 Lindell Boulevard \\ St. Louis, MO 63103 \\ United States of America \\ brian.boutwell@slu.edu
}




\title{
Could Peers Influence Intelligence during Adolescence? An Exploratory Study
}

\begin{abstract}
For decades, scholars have examined various aspects concerning the development of intelligence. Little research, however, has considered the potential for peers to influence intellectual ability. To investigate this possibility, data collected on a sample of 892 adolescents and their best friends who participated in the Study of Early Child Care and Youth Development were analyzed. Results indicate that while a large bivariate association exists in a longitudinal model between peer and adolescent intelligence, it is reduced to non-significance after controlling for prior levels of adolescent intelligence and other background variables. As such, and contrary to a number of other literatures providing evidence of peer influences on developmental outcomes during adolescence, this study does not find evidence supporting a socialization effect of peers on intellectual ability. Limitations of the study and directions for future research are discussed.
\end{abstract}

Keywords: intelligence; friendships; adolescence; socialization; SECCYD 
Well known is the parochial observation that "birds of a feather flock together." Such insight accords with evidence suggesting that friends and mates tend to be similar across a variety of outcomes (e.g., Burgess, Sanderson, \& Umaña-Aponte, 2011). Peers, moreover, might also exert lasting effects on developmental outcomes, even despite strong selection effects (e.g., Borsari \& Carey, 2001; Harris, 1995; 1998; Meldrum \& Hay, 2012; Reitz, Zimmermann, Hutteman, Specht, \& Neyer, 2014; Van de Bongardt, Reitz, Sandfort, \& Deković, 2015; van de Weijer \& Beaver, 2017). To use the classic example of peer culture, children of immigrants, despite hearing their native language at home, will nonetheless acquire the language and accent of their peers (see Harris, 1998). Beyond this, scholars have examined the effects of peers on traits ranging from self-control (Meldrum \& Hay, 2012) to criminal behavior (Pratt et al., 2010; van de Weijer \& Beaver, 2017). Conspicuously absent from prior research, however, are efforts to examine whether peers have any influence on intelligence. To be sure, there is evidence of self-selection for intelligence in relationship formation (Boutwell et al., 2017; Plomin \& Deary, 2015; Ritchie, 2015). Yet, there is very little research directly examining whether being friends with more intelligent peers may positively influence one's own intelligence.

\section{Peers and Intelligence}

As noted, there is compelling evidence of similarity in intelligence between friends. Burgess and colleagues (2011), for example, reported that children's IQs were significantly correlated with their current friends' IQs at both age 8 and 16 years old in a sample of almost 7,000 individuals. More recently, Boutwell and colleagues (2017) evaluated this topic by analyzing intelligence levels of 810 fourth graders along with intelligence levels of each subject's best friend. Their results showed that preadolescent friendship dyads are concurrently 
correlated on measures of intelligence $(b=0.36)$, and this association is evident across both race and sex subgroups.

Some of the key correlates of intelligence, such as academic achievement, have also become increasingly of interest to researchers in this area (Barnes, Beaver, Young, \& TenEyck, 2014; Bates \& Gupta, 2017; Burgess et al., 2011). Analysis of a national sample of about 10,000 American youth found that an individual's grade point average was significantly correlated with peer GPA ( $b=.31$; Barnes et al., 2014; see also Hamm, 2000), and other research supports the contention of socialization effects of peers on GPA (Rambaran et al., 2017; Shin \& Ryan, 2014; but see Wentzel et al., 2004). Given the above strands of research, there is clear evidence that a correlation exists between the intelligence levels (and GPA) of friends. What is less clear is whether a long-term association between peer and adolescent intelligence emerges, once prior levels of intelligence have been taken into account. As we discuss below, there is reason to suspect that such a relation could exist.

\section{Group Socialization Theory \& Reasons to Anticipate Peer Effects on Intelligence}

From a theoretical vantage point, Harris (1995) proposed a theory of personality intended to unite key findings from multiple domains. At the time, the prevailing assumption among many developmental scholars was that parental influences were the essential factor in understanding the long-term development of personality (see Harris, 1998; Barbaro et al., 2017). Yet, findings from quantitative genetic studies repeatedly revealed a paucity of variance attributable to family-level effects (Turkheimer, 2000; Rowe, 1994). Nonetheless, those studies did reveal the importance of environmental influences unique to each child within the family (Turkheimer, 2000). 
What emerged was "Group Socialization Theory" (GST; Harris, 1995), in which peer groups were proposed to represent the primary socializing force for children over the long term. The argument was straightforward in that it supposed "socialization" to first involve a child's tendency to "niche pick" within their circle of peers. Additionally, Harris (1995) considered "context specificity" to be a key component in that children were capable of adapting to a given situation, such as adapting to a particular available niche in a peer group. Personality traits and behavioral tendencies are then further shaped based on the culture and behavior of the child's peers.

Absent from the original version of GST, however, was a direct discussion of intelligence. Yet, two qualities of intelligence suggest an implicit prediction that GST could make about peers and possible effects on intellectual ability. The first aspect of intelligence concerns the relative impact of genetic and environmental influences across the life span. Specifically, the heritability of intelligence is modest in childhood, accompanied by some shared environmental effects (Plomin \& Deary, 2015). Yet, across development, heritable effects quickly increase, shared environmental effects decline, and nonshared environmental effects remain (Plomin \& Deary, 2015). The apparent contribution of nonshared environmental effects during adolescence suggests that key variables outside the family should be investigated, and Harris's work highlights peers as a possible candidate for study.

The second quality of intelligence that warrants mention is the distinction between fluid and crystallized intelligence. Friends could influence each other's crystallized intellectual abilities in particular — the use of prior knowledge and experience to solve problems — which tends to continue development longer into the life course than fluid intellectual abilities (see Ritchie, 2015; Salthouse, 2004). Thus, it is plausible that individuals, despite self-selecting into 
their friendships based on similarity in intelligence, could nonetheless experience a socialization effect of their friends' cognitive abilities that improves their crystallized, and perhaps to a lesser extent fluid, intelligence.

We see at least two possible pathways through which such socialization may occur. First, associating with more intelligent peers could contribute to intellectual ability by exposing an adolescent to cultural values favorable to learning and, more importantly, to the application and use of knowledge to solve problems (i.e., crystallized intelligence), given that more intelligent peers are more academically inclined (e.g., Deary, Strand, Smith, \& Fernandes, 2007). Indeed, prior research has found an association between peer academic engagement and subject's own motivation (Kindermann, 2007), even longitudinally (Molloy, Gest, \& Rulison, 2011; but see Véronneau \& Dishion, 2011). Second, and related to the first point, having more intelligent peers may shape one's own intelligence directly by further facilitating knowledge acquisition. Having more intelligent peers may buttress the efforts of teachers by providing aids when an adolescent is struggling to understand something. Such assistance may not be as available if one associates with less intelligent peers, who may also be struggling with mastering the same material, and thus are not well positioned to offer assistance with a particular subject. Overall, the first pathway suggests a passive form of peer socialization leading to gains in crystallized intelligence, whereas the second pathway suggests an active form of peer socialization.

\section{THE CURRENT STUDY}

The current study seeks to test an understudied yet important question. Specifically, are longitudinal correlations between peer and adolescent intelligence indicative of peer influences on intelligence? While we cannot reach any strong causal conclusions with the observational data we employ, a socialization effect could be evident if peer correlations persist once the 
stability of intelligence and other background factors are taken into account. Based on prior research, we anticipate that a substantive portion of the association between peer and adolescent intelligence will be accounted for by prior intelligence. Yet we also hypothesize, based on the arguments made above concerning possible peer socialization effects, that a positive association between peer and adolescent intelligence will remain, even when accounting for prior intelligence and other background factors.

\section{METHOD}

\section{Data}

In order to provide an initial test of our hypothesis, we analyzed data from the National Institute of Child Health and Human Development's Study of Early Child Care and Youth Development (SECCYD), which followed a sample of over 1,000 U.S. families from the birth of a child in 1991 to the time the child was 15 years old. Readers are directed to prior discussions of the SECCYD (Boutwell et al., 2017; NICHD Early Child Care Research Network, 2001) for information on its sampling design, but we will note here that, for the current study, we utilize data up to and including the age 15 assessment period. Permission to access and use the SECCYD data (hosted by the Inter-University Consortium for Political and Social Research) was granted by the lead author's institutional review board under exempt status (IRB exemption \# 082610-00).

\section{Measures}

Adolescent Crystallized Intelligence. At multiple points during the SECCYD, participants completed a variety of tests at assessment centers, some of which gauge intelligence. Pertinent to our focus, when study children were 15 years old they completed three WoodcockJohnson Psycho-educational Battery -Revised (WJ-R; Woodcock \& Johnson, 1989) tests: picture 
vocabulary (PV), passage comprehension (PC), and applied problems (AP). The standardized scores for each of the three tests administered at age 15 were used to construct a latent variable measuring intelligence. It should be noted that variation in the WJ-R scores largely capture crystallized intelligence (see Ritchie, 2015), however, still represent variation in aspects of fluid intelligence.

Best Friend Intelligence. When study children were in the sixth grade, their best friend completed a variety of inventories at an assessment center. The identification and recruitment of the child's best friend was based on discussion with mothers and input from the study children. The selection criteria required that the friend be of similar age to the study child, with additional preference being given to 1) a same sex best friend, 2) whom the study child had known for at least six weeks and, 3) whom the study child spends time with at least once per week. The intelligence of each friend at sixth grade was assessed using the Peabody Picture Vocabulary Test III (PPVT-III; Dunn \& Dunn, 1997). The PPVT-III is a vocabulary test that exists in two parallel forms, form IIIA and IIIB. Only form IIIA, however, was used in the SECCYD. Using age-based norms, standardized scores were created with a mean of 100 and a standard deviation of 15 .

Covariates. At fifth grade, study children completed the same three WJ-R tests described above (i.e., PV, PC, and AP) used to measure the dependent variable at age 15. As was true for the measurement of intelligence at age 15 , the standardized scores for each of the three tests at fifth grade were used to create a latent construct measuring crystallized intelligence. Controlling for prior intelligence is critical to accounting for potential self-selection into the friendship, at least with regard to similarity in intelligence, and enables us to determine if best friend 
intelligence during the sixth grade is associated with changes in intelligence from grade five to age 15 .

We also control for a range of variables known to be correlated with child intelligence, and which could also be associated with friendship selection. First, maternal education when study children were one month old was measured on an ordinal scale ranging from a low score of 1 (less than high school) to a high score of 5 (advanced degree). Second, we control for maternal intelligence using standardized scores for the Peabody Picture Vocabulary Test Revised (PPVT-R; Dunn \& Dunn, 1981), completed by mothers when study children were three years old. Third, we control for nine other variables. These include the child's race (non-White $=1$, all others $=0), \operatorname{sex}($ Male $=1$, Female $=0)$, and family structure when study children were one month old (two-parent nuclear families $=1$, all other family types $=0$ ). We also control for the mother's age at the birth of the focal child (in years); birth order; the child's birth weight in grams; if the family was receiving public assistance when the child was born $(\mathrm{Yes}=1$, No $=0$ ); maternal depression (based on scores from the Center for Epidemiological Studies Depression Scale) when the child was one month old; and an ordinal measure for whether the pregnancy was planned $(0=$ neither parents were planning, $1=$ one parent was planning, $2=$ both parents were planning). Given the 1991 birth cohort design of the SECCYD, age is treated as a constant. Lastly, we control for two indicators of cognitive stimulation when children were six months old. During a home visit, trained observers recoded information using the Home Observation for Measurement of the Environment (HOME; Caldwell \& Bradley, 1984). The SECCYD researchers constructed a 9-item home enrichment variable tapping into such things as: whether the child has 3 or more books of his/her own and whether the mother structures play periods. Each item was scored dichotomously $(\mathrm{Yes}=1, \mathrm{No}=0)$, and the scores were added 
together to create an index ranging from zero to nine. The second indicator, maternal stimulation, is based on a videotaped mother-child interaction task completed in the home consisting of sessions of 15 minutes of free play between the mother and the child, divided into two episodes. Trained raters scored the quality and frequency of the mother's effort to facilitate the child's cognitive development on a scale from one to four. The descriptive statistics for each of the variables included in the analysis, before considerations of missing data, can be found in Table 1.

-- Table 1 about here --

\section{Analytic Strategy}

To examine whether there is any association between best friend intelligence and adolescent intelligence after accounting for prior intelligence and other background factors, we estimate a series of structural equation models using manifest measures of intelligence as indicators of a latent variable measured at the two waves of data collection (i.e., fifth grade and age 15). This allows us to examine whether change in intelligence between the two times points covaries with best friend intelligence measured at sixth grade. In addition, we include correlations among the error terms for the same indicators measured at each time point to account for serial correlation in the disturbances. Appendix A shows that the factor loadings for each indicator of the latent factor of intelligence are large and that the latent factors at each time point covary. The model fit suggests that the measurement model for intelligence fit the data very well.

Attrition and missing data. The SECCYD sample consisted of 1,364 cases when the study began in 1991. Due to attrition and missing data, however, 335 cases did not have measures of intelligence at either grade five or age 15, and an additional 137 cases did not have 
all three measures of intelligence (i.e., grade five focal respondent intelligence, grade six peer intelligence, and age 15 focal respondent intelligence). These 472 cases are excluded from the analysis. The remaining 892 cases serve as the effective sample used in the analysis. Of these adolescents, $49.5 \%$ are male, $18.4 \%$ are non-White, $74.1 \%$ come from traditional two-parent biological households, and $16.1 \%$ live in a household that was receiving some form of public assistance at the time they were born.

For the estimated models, we use full information maximum likelihood (FIML) by selecting the "mlmv" option within the sem command in Stata 15.0 (StataCorp., 2017). The "mlmv" option in Stata 15.0 assumes multivariate normality and that data are missing at random, conditional on the observed data. For information on differences between the 892 cases analyzed and the 472 excluded cases on the variables measured at the beginning of the SECCYD, readers are referred to Appendix B. Briefly, excluded cases scored lower on maternal education, were slightly more likely to be male, more likely to have non-traditional family structures, more likely to have younger mothers, had higher birth orders, and were more likely to be receiving public assistance; no statistically significant differences between included and excluded cases emerged with regard to race, birth weight, maternal depression, or whether the pregnancy was planned.

Model Fit. Several fit indices are used to evaluate model fit for the structural equations estimated. In addition to the conventional $\chi^{2}$ test statistic, the root mean squared error of approximation (RMSEA) (Steiger, 1990) is used because it takes into account the sample size to correct for the tendency of the $\chi^{2}$ to reject models with large samples. Values less than 0.05 are good and values between 0.05 and 0.08 are viewed as acceptable. The non-normed fit index (NNFI) (Bentler \& Bonett, 1980) takes into account the number of parameters in a model to 
adjust for the tendency for fit indices to increase as the size of the model increases. Values of 0.90 to 0.95 are considered acceptable and values greater than 0.95 are considered good. The comparative fit index (CFI) (Bentler, 1990) has the same goodness of fit criteria as the NNFI.

\section{RESULTS}

A series of structural equation models estimated to test our hypothesis are reported in Table 2. Model 1 indicates that, in the absence of any covariates, a large association exists between best friend intelligence at sixth grade and adolescent intelligence at age 15 . Specifically, a one standard deviation (SD) increase in best friend intelligence is associated with a $0.505 \mathrm{SD}$ increase $(p<.001)$ in adolescent intelligence approximately three years later. Turning to Model 2, which adds each of the covariates to the model with the exception of prior intelligence, the magnitude of the association between peer intelligence at sixth grade and adolescent intelligence at age 15 is reduced by approximately $50 \%$, yet it remains statistically significant $(\beta=0.245, p<$ $.001)$. In addition, several of the covariates are associated with adolescent intelligence at age 15: maternal education $(\beta=0.125, p<.001)$, maternal intelligence $(\beta=0.334, p<.001)$, birth order $(\beta=-0.136, p<.001)$, birth weight $(\beta=0.056, p<.05)$, and home enrichment scores $(\beta=0.069$, $p<.05)$.

-- Table 2 about here --

Model 3 adds the measure of prior intelligence assessed at fifth grade. As shown, the association between best friend intelligence at sixth grade and adolescent intelligence at age 15 is almost entirely reduced to zero and is no longer statistically significant when accounting for prior adolescent intelligence at fifth grade $(\beta=0.039, p>.05)$, which is contrary to our stated hypothesis. In contrast, and indicative of a great degree of stability in intelligence across adolescence, the association between adolescent intelligence at fifth grade and at age 15 is very 
large $(\beta=0.884, p<.001)$. Furthermore, the standardized covariance from the measurement model of the two latent factors for intelligence is 0.93 , indicating that roughly $86 \%$ of the variation in intelligence measured at age 15 is explained by the measurement taken at fifth grade. Though the measure shows a great deal of stability, one covariate emerged as a statistically significant (though not substantive) predictor of adolescent intelligence in Model 3: a planned pregnancy $(\beta=0.043, p<.05)$.

\section{DISCUSSION}

Decades of research have revealed clear associations between indicators of intelligence and a host of outcomes (e.g., Beaver et al., 2016; Deary, Strand, Smith, \& Fernandes, 2007; Deary, Weiss, \& Batty, 2010; Der, Batty, \& Deary, 2009; Gottfredson, 1997; Strenze, 2007). It is not surprising, then, that numerous studies have examined the factors that contribute to the development of intelligence (e.g., Haier, 2016; Plomin \& Deary, 2015). The current study sought to contribute to this body of research by providing a theoretical rationale for and initial test of the potential influence of peers on intelligence during adolescence, which heretofore is a topic that has been largely neglected.

Overall, the results of our exploratory analysis do not support the hypothesis that having a more intelligent best friend influences one's own intelligence during adolescence. To be clear, while a large bivariate association was found, once prior intelligence and the other background factors were controlled, the observed association between best friend intelligence and later adolescent intelligence was reduced to a small association that was not statistically significant ( $\beta$ $=0.039, p>.05)$. Thus, our findings provide evidence indicating that the correlation between peer and adolescent intelligence found in prior work (see Boutwell et al., 2017; Burgess et al., 2011) are likely to be the product of adolescents becoming friends with others who are similar to 
themselves on intellectual ability as opposed to peer effects on intelligence. Further, the very large association between intelligence in early adolescence and in middle adolescence found in this study $(\beta=0.884, p<.001)$ is indicative of the high degree of relative stability during this period noted by other researchers (see Plomin \& Deary, 2015).

\section{Limitations and Future Research}

Despite the strengths of our analysis, future research will be helpful in assessing the replicability of our results in other samples and with participants of other ages. In addition, we see three key limitations of the current study arising from a reliance on secondary data which may have limited our ability to detect peer influence effects, assuming any are there to be found. First, the measure of peer intelligence (i.e., PPVT scores) available in the data was different from the measure of adolescent intelligence (i.e., WJ-R scores). Greater parity in the measures of peer and adolescent intelligence may provide stronger evidence suggestive of a socialization effect. Second, the time lag between the measurement of peer intelligence and later adolescent intelligence was approximately three years. With no information available on whether the friendships in the sixth grade were maintained up to age 15 , it is possible that a portion of the friendships under consideration might have dissolved well before study children reached the age of 15 , which may attenuate any socialization effect.

Third, future research should include more than one peer in the analysis. While it seems reasonable to assume that a best friend may have the greatest potential influence on intelligence, as has been suggested for other outcomes (e.g., delinquency; Weerman \& Smeenk, 2005), it will be important to understand if additional peers, or even the average cognitive ability of a friendship network, may impact one's own capabilities (see also Bates \& Gupta, 2017). As an additional consideration, future research seeking to differentiate between selection and influence 
effects within friendship networks would benefit from the use of stochastic actor-based modeling techniques (e.g., Gallupe, McLevey, \& Brown, 2018; Weerman, 2011).

With the above caveats in mind, we view this exploratory study as an interesting indication that peers may have limited influence on one's intellectual capabilities during adolescence, which stands in contrast to findings from other disciplines indicating that peers may influence a variety of developmental outcomes (Borsari \& Carey, 2001; Harris, 1995; 1998; Meldrum \& Hay, 2012; Reitz et al., 2014; Van de Bongardt et al., 2015; van de Weijer \& Beaver, 2017). Yet, given the paucity of research investigating the potential influence of peers on intelligence, combined with our observations pointing to ways in which future research can work to overcome the limitations of this exploratory study, we believe research on the etiology and development of intelligence could benefit by extending its gaze beyond the effects of genes, the rearing environment, and formal education, and focusing too on the potential role of peers. 


\section{REFERENCES}

Barbaro, N., Boutwell, B. B., Barnes, J. C., \& Shackelford, T. K. (2017). Rethinking the transmission gap: What behavioral genetics and evolutionary psychology mean for attachment theory: A comment on Verhage et al.(2016). Psychological Bulletin, 143, 107-113. https://doi.org/10.1037/bul0000066

Barnes, J. C., Wright, J. P., Boutwell, B. B., Schwartz, J. A., Connolly, E. J., Nedelec, J. L., \& Beaver, K. M. (2014). Demonstrating the validity of twin research in criminology. Criminology, 52, 588-626. https://doi.org/10.1111/1745-9125.12049

Bates, T. C., \& Gupta, S. (2017). Smart groups of smart people: Evidence for IQ as the origin of collective intelligence in the performance of human groups. Intelligence, 60, 46-56. https://doi.org/10.1016/j.intell.2016.11.004

Beaver, K. M., Schwartz, J. A., Connolly, E. J., Said Al-Ghamdi, M., Kobeisy, A. N., Barnes, J. C., \& Boutwell, B. B. (2016). Intelligence and early life mortality: Findings from a longitudinal sample of youth. Death Studies, 40, 298-304. https://doi.org/10.1080/07481187.2015.1137994

Bentler, P. M. (1990). Comparative fit indexes in structural models. Psychological Bulletin, 107, 238-246. http://psycnet.apa.org/doi/10.1037/0033-2909.107.2.238

Bentler, P. M., \& Bonett, D.G. (1980). Significance tests and goodness of fit in the analysis of covariance structures. Psychological Bulletin, 88, 588-606. http://psycnet.apa.org/doi/10.1037/0033-2909.88.3.588

Boutwell, B. B., Meldrum, R. C., \& Petkovsek, M. A. (2017). General intelligence in friendship selection: A study of preadolescent best friend dyads. Intelligence, 64, 30-35. https://doi.org/10.1016/j.intell.2017.07.002 
Burgess, S., Sanderson, E., \& Umana-Aponte, M. (2011). School ties: An analysis of homophily in an adolescent friendship network. University of Bristol. Retrieved from: http://www.bristol.ac.uk/cmpo/publications/papers/2011/wp267.pdf

Borsari, B., \& Carey, K. B. (2001). Peer influences on college drinking: A review of the research. Journal of Substance Abuse, 13, 391-424. https://doi.org/10.1016/S08993289(01)00098-0

Caldwell, B.M., \& Bradley, R.H. (1984). Home Observation for Measurement of the Environment. University of Arkansas at Little Rock. Little Rock, AR.

Deary, I. J., Strand, S., Smith, P., \& Fernandes, C. (2007). Intelligence and educational achievement. Intelligence, 35, 13-21. https://doi.org/10.1016/j.intell.2006.02.001

Deary, I. J., Weiss, A., \& Batty, G. D. (2010). Intelligence and personality as predictors of illness and death: How researchers in differential psychology and chronic disease epidemiology are collaborating to understand and address health inequalities. Psychological Science in the Public Interest, 11, 53-79. https://doi.org/10.1177/1529100610387081

Der, G., Batty, G. D., \& Deary, I. J. (2009). The association between IQ in adolescence and a range of health outcomes at 40 in the 1979 US National Longitudinal Study of Youth. Intelligence, 37, 573-580. https://doi.org/10.1016/j.intell.2008.12.002

Dunn, L. M., \& Dunn, L. M. (1981). Manual for the peabody picture vocabulary testrevised. Circle Pines, MN: American Guidance Service.

Dunn, L. M., \& Dunn, L. M. (1997). PPVT-III: Peabody picture vocabulary test. Circle Pines, MN: American Guidance Service. 
Gallupe, O., McLevey, J. \& Brown, S. J. (In Press). Selection and influence: A meta-analysis of the association between peers and personal offending. Journal of Quantitative Criminology. https://doi.org/10.1007/s10940-018-9384-y

Gottfredson, L. S. (1997). Why g matters: The complexity of everyday life. Intelligence, 24, 79132. https://doi.org/10.1016/S0160-2896(97)90014-3

Haier, R. J. (2016). The neuroscience of intelligence. New York, NY: Cambridge University Press.

Hamm, J. V. (2000). Do birds of a feather flock together? The variable bases for African American, Asian American, and European American adolescents' selection of similar friends. Developmental Psychology, 36, 209-219. http://dx.doi.org/10.1037/00121649.36.2.209

Harris, J. R. (1995). Where is the child's environment? A group socialization theory of development. Psychological Review, 102, 458-489. http://psycnet.apa.org/doi/10.1037/0033-295X.102.3.458

Harris, J. (1998). The nurture assumption: Why children turn out the way they do. New York: Touchstone.

Kindermann, T. A. (2007). Effects of naturally existing peer groups on changes in academic engagement in a cohort of sixth graders. Child Development, 78, 1186-1203. https://doi.org/10.1111/j.1467-8624.2007.01060.x

Meldrum, R. C., \& Hay, C. (2012). Do peers matter in the development of self-control? Evidence from a longitudinal study of youth. Journal of Youth and Adolescence, 41, 691-703. https://doi.org/10.1007/s10964-011-9692-0 
Molloy, L. E., Gest, S. D., \& Rulison, K. L. (2011). Peer influences on academic motivation: Exploring multiple methods of assessing youths" most "influential" peer relationships. The Journal of Early Adolescence, 31(1), 13-40. https://doi.org/10.1177/0272431610384487

NICHD Early Child Care Research Network. (2001). Nonmaternal care and family factors in early development: An overview of the NICHD study of early child care. Applied Developmental Psychology, 22,457-492. https://doi.org/10.1016/S0193-3973(01)00092-2

Plomin, R., \& Deary, I. J. (2015). Genetics and intelligence differences: five special findings. Molecular Psychiatry, 20, 98-108. doi:10.1038/mp.2014.105

Pratt, T. C., Cullen, F. T., Sellers, C. S., Thomas Winfree Jr, L., Madensen, T. D., Daigle, L. E., Fearn, N. E., \& Gau, J. M. (2010). The empirical status of social learning theory: A metaanalysis. Justice Quarterly, 27, 765-802. https://doi.org/10.1080/07418820903379610

Rambaran, J. A., Hopmeyer, A., Schwartz, D., Steglich, C., Badaly, D., \& Veenstra, R. (2017). Academic functioning and peer influences: A short-term longitudinal study of networkbehavior dynamics in middle adolescence. Child Development, 88, 523-543. https://doi.org/10.1111/cdev.12611

Reitz, A. K., Zimmermann, J., Hutteman, R., Specht, J., \& Neyer, F. J. (2014). How peers make a difference: The role of peer groups and peer relationships in personality development. European Journal of Personality, 28, 279-288. DOI: 10.1002/per.1965

Ritchie, S. J. (2015). Intelligence: All that matters. Hodder \& Stoughton.

Rowe, D. C. (1994). The limits of family influence: Genes, experience, and behavior. Guilford Press. 
Salthouse, T. A. (2004). What and when of cognitive aging. Current Directions in Psychological Science, 13, 140-144. https://doi.org/10.1111/j.0963-7214.2004.00293.x

Shin, H., \& Ryan, A. M. (2014). Early adolescent friendships and academic adjustment: Examining selection and influence processes with longitudinal social network analysis. Developmental Psychology, 50, 2462-2472. https://doi.org/10.1037/a0037922

StataCorp. 2017. Stata Statistical Software: Release 15. College Station, TX: StataCorp LLC.

Steiger, J. H. (1990). Structural model evaluation and modification: An interval estimation approach. Multivariate Behavioral Research, 25, 173-180. https://doi.org/10.1207/s15327906mbr2502_4

Strenze, T. (2007). Intelligence and socioeconomic success: A meta-analytic review of longitudinal research. Intelligence, 35, 401-426. https://doi.org/10.1016/j.intell.2006.09.004

Turkheimer, E. (2000). Three laws of behavior genetics and what they mean. Current Directions in Psychological Science, 9, 160-164. https://doi.org/10.1111/1467-8721.00084

Van de Bongardt, D., Reitz, E., Sandfort, T., \& Deković, M. (2015). A meta-analysis of the relations between three types of peer norms and adolescent sexual behavior. Personality and Social Psychology Review, 19, 203-234. https://doi.org/10.1177/1088868314544223

van de Weijer, S. G., \& Beaver, K. M. (2017). An exploration of mate similarity for criminal offending behaviors: Results from a multi-generation sample of Dutch spouses. Psychiatric Quarterly, 88, 523-533. https://doi.org/10.1007/s11126-016-9465-8

Véronneau, M. H., \& Dishion, T. J. (2011). Middle school friendships and academic achievement in early adolescence: A longitudinal analysis. The Journal of Early Adolescence, 31, 99-124. https://doi.org/10.1177/0272431610384485 
Weerman, F. M. (2011). Delinquent peers in context: A longitudinal network analysis of selection and influence effects. Criminology, 49, 253-286. https://doi.org/10.1111/j.17459125.2010.00223.x

Weerman, F. M., \& Smeenk, W. H. (2005). Peer similarity in delinquency for different types of friends: A comparison using two measurement methods. Criminology, 43, 499-524. DOI: 10.1111/j.0011-1348.2005.00015.x

Wentzel, K. R., Barry, C. M., \& Caldwell, K. A. (2004). Friendships in middle school: Influences on motivation and school adjustment. Journal of Educational Psychology, 96, 195-203. http://psycnet.apa.org/doi/10.1037/0022-0663.96.2.195

Woodcock, R.W., \& Johnson, M. B. (1989). Woodcock-Johnson psycho-educational batteryrevised. Allen, TX: Developmental Learning Materials. 
Table 1. Descriptive Statistics

\begin{tabular}{|c|c|c|c|c|c|}
\hline Variable & $\mathrm{N}$ & $\begin{array}{c}\text { Mean/ } \\
\text { Proportion }\end{array}$ & SD & Min & $\operatorname{Max}$ \\
\hline \multicolumn{6}{|l|}{ Child/Adolescent Intelligence Measures } \\
\hline Grade 5 WJ-R Picture Vocabulary & 992 & 103.09 & 14.78 & 29 & 155 \\
\hline Grade 5 WJ-R Passage Comprehension & 991 & 105.39 & 12.33 & 29 & 151 \\
\hline Grade 5 WJ-R Applied Problems & 993 & 109.31 & 13.54 & 37 & 156 \\
\hline Age 15 WJ-R Picture Vocabulary & 889 & 99.93 & 14.77 & 34 & 158 \\
\hline Age 15 WJ-R Passage Comprehension & 887 & 107.71 & 15.72 & 44 & 160 \\
\hline Age 15 WJ-R Applied Problems & 887 & 102.92 & 14.22 & 48 & 168 \\
\hline \multicolumn{6}{|l|}{ Best Friend Intelligence } \\
\hline Grade 6 (PPVT) & 915 & 109.08 & 14.85 & 61 & 155 \\
\hline \multicolumn{6}{|l|}{ Covariates } \\
\hline Maternal Education & 1363 & 3.08 & 1.18 & 1 & 5 \\
\hline Maternal Intelligence (PPVT-R) & 1167 & 99.01 & 18.35 & 40 & 159 \\
\hline Male $(=1)$ & 1364 & $52 \%$ & --- & --- & --- \\
\hline Non-White (=1) & 1364 & $20 \%$ & --- & --- & --- \\
\hline Family Structure (2-parent nuclear $=1)$ & 1364 & $71 \%$ & --- & --- & --- \\
\hline Maternal Age at Birth of Child & 1364 & 28.11 & 6.63 & 18 & 46 \\
\hline Birth Order & 1364 & 1.83 & 0.95 & 1 & 7 \\
\hline Birth Weight (g) & 1364 & 3489.52 & 506.58 & 2000 & 5428 \\
\hline Public Assistance (=1) & 1364 & $19 \%$ & --- & --- & --- \\
\hline Maternal Depression & 1363 & 11.36 & 9.02 & 0 & 53 \\
\hline Planned Pregnancy & 1360 & 1.16 & 0.93 & 0 & 2 \\
\hline Home Enrichment Score & 1279 & 6.50 & 1.97 & 0 & 9 \\
\hline Maternal Stimulation & 1272 & 2.59 & 0.65 & 1 & 4 \\
\hline
\end{tabular}

Notes: WJ-R = Woodcock Johnson-Revised, PPVT-R = Peabody Picture Vocabulary Test Revised 
Table 2. Structural Equation Model of Intelligence at Age $15(\mathrm{~N}=892)$

\begin{tabular}{|c|c|c|c|c|c|c|c|c|c|}
\hline & \multicolumn{3}{|c|}{ Model 1} & \multicolumn{3}{|c|}{ Model 2} & \multicolumn{3}{|c|}{ Model 3} \\
\hline & $\mathrm{b}$ & SE & $B$ & $\mathrm{~b}$ & SE & $B$ & $\mathrm{~b}$ & SE & $B$ \\
\hline Peer Intelligence Grade 6 & $0.392 * * *$ & 0.028 & 0.505 & $0.197 * * *$ & 0.027 & 0.245 & 0.031 & 0.019 & 0.039 \\
\hline Mother Education & ----- & ----- & ----- & $1.311 * * *$ & 0.409 & 0.125 & 0.366 & 0.279 & 0.035 \\
\hline Maternal Intelligence & ----- & ----- & ----- & $0.218 * * *$ & 0.025 & 0.334 & 0.013 & 0.018 & 0.021 \\
\hline Male & ----- & ----- & ----- & 0.923 & 0.699 & 0.038 & 1.006 & 0.501 & 0.093 \\
\hline Nonwhite & ----- & ----- & ----- & -0.757 & 1.038 & -0.024 & -0.018 & 0.703 & -0.001 \\
\hline Family Structure & ----- & ----- & ----- & 2.036 & 0.956 & 0.073 & 0.372 & 0.644 & 0.013 \\
\hline Maternal Age at Birth & ----- & ----- & ----- & 0.135 & 0.082 & 0.062 & 0.004 & 0.056 & 0.001 \\
\hline Birth Order & ----- & ----- & ----- & $-1.85 * * *$ & 0.422 & -0.136 & 0.290 & 0.293 & 0.021 \\
\hline Birth Weight (g) & ----- & ----- & ----- & $1.357^{*}$ & 0.690 & 0.056 & 0.173 & 0.469 & 0.007 \\
\hline Public Assistance & ----- & ----- & ----- & 0.219 & 1.076 & 0.006 & -0.316 & 0.730 & -0.009 \\
\hline Planned Pregnancy & ----- & ----- & ----- & -0.266 & 0.399 & -0.020 & $0.574 *$ & 0.273 & 0.043 \\
\hline Home Enrichment Score & ----- & ----- & ----- & $0.441 *$ & 0.203 & 0.069 & -0.031 & 0.138 & -0.004 \\
\hline Maternal Stimulation & ---- & ---- & ----- & -0.233 & 0.559 & -0.012 & -0.117 & 0.374 & -0.006 \\
\hline \multicolumn{10}{|l|}{ Autoregressive Term } \\
\hline Prior intelligence Grade 5 & ----- & ----- & ----- & ----- & ----- & ----- & $0.909 * * *$ & 0.049 & 0.884 \\
\hline \multicolumn{10}{|l|}{ Model Fit } \\
\hline R-Squared & \multicolumn{3}{|c|}{0.255} & \multicolumn{3}{|c|}{0.497} & \multicolumn{3}{|c|}{0.935} \\
\hline Chi-Squared & \multicolumn{3}{|c|}{15} & \multicolumn{3}{|c|}{120} & \multicolumn{3}{|c|}{214} \\
\hline RMSEA & \multicolumn{3}{|c|}{0.086} & \multicolumn{3}{|c|}{0.061} & \multicolumn{3}{|c|}{0.053} \\
\hline NNFI & \multicolumn{3}{|c|}{0.970} & \multicolumn{3}{|c|}{0.913} & \multicolumn{3}{|c|}{0.940} \\
\hline CFI & \multicolumn{3}{|c|}{0.990} & \multicolumn{3}{|c|}{0.946} & \multicolumn{3}{|c|}{0.963} \\
\hline
\end{tabular}

$* \mathrm{p}<.05, * * \mathrm{p}<.01, * * * \mathrm{p}<.001$ (two-tailed) 
Appendix A. Measurement Model for IQ

\begin{tabular}{lcc}
\hline Factor Loadings & IQ Grade 5 & IQ Age 15 \\
\hline Picture vocabulary & 0.764 & 0.779 \\
Passage comprehension & 0.825 & 0.897 \\
Applied problems & 0.724 & 0.741 \\
\hline
\end{tabular}

\begin{tabular}{lcc} 
Variance/Covariance Matrix & IQ Grade 5 & IQ Age 15 \\
\hline IQ Grade 5 & 124.513 & ---- \\
IQ Age 15 & 120.069 & 131.821 \\
& & \\
Model Fit & \\
\hline Chi-Squared & 19 \\
RMSEA & 0.058 \\
NNFI & 0.987 \\
CFI & 0.996 \\
\hline
\end{tabular}


Appendix B. Difference of Means or Proportions for Analytic Sample $(n=892)$ and Excluded Cases $(n=472)$ for variables measured at start of the Study of Early Child Care and Youth Development

\begin{tabular}{lcccc}
\hline Variables & Analytic Sample & Excluded Cases & Difference & 2 tailed p-value \\
\hline Maternal Education & 3.190 & 2.883 & 0.307 & 0.000 \\
Male & 0.495 & 0.557 & -0.061 & 0.030 \\
Nonwhite & 0.184 & 0.216 & -0.031 & 0.168 \\
Family Structure & 0.741 & 0.648 & 0.092 & 0.000 \\
Maternal Age at Birth & 28.635 & 27.116 & 1.519 & 0.000 \\
Birth Order & 1.785 & 1.921 & -0.135 & 0.011 \\
Birth Weight (kg) & 3.498 & 3.472 & 0.026 & 0.363 \\
Public Assistance & 0.161 & 0.239 & -0.077 & 0.000 \\
Maternal Depression & 11.087 & 11.884 & -0.797 & 0.120 \\
Planned Pregnancy & 1.193 & 1.106 & 0.086 & 0.101 \\
\hline
\end{tabular}

